\title{
CHRONIC PULMONARY FAILURE
}

\author{
By C. H. Fitrs, M.D., F.R.C.P. \\ Honorary Physician, Royal Melbourne Hospital; Honorary Physician, Thoracic Department, \\ Austin Hospital for Chronic Diseases
}

About 15 years ago I was asked to report on the cardiovascular state of a man of 48 , almost crippled for want of breath, in whom no adequate reason for the disorder could be found. This man had passed unscathed through the First World War, and since then had farmed successfully a sheep station of 50,000 acres. His land bordered what is called the 'back country.' It is a land of richness in good seasons, but subject to prolonged and terrible droughts. It is a dry and healthy climate. Until he reached the middle forties, he never spared himself and never recalled being ill. Gradually thereafter he became vaguely aware that all was not well and he was easily exhausted. So rapidly had this feeling increased over the last I 2 months that as I watched him, he was painfully distressed at the mere effort of removing his shirt. Yet had I turned away, I would have been unaware of this distress for the dyspnoea was almost noiseless.

He stood there stripped, over 6 feet in height, and gaunt almost to the point of emaciation. His neck muscles tugged at his upper chest and his abdomen caved in with the inspiratory effort. Not only did his chest seem fixed but the skin was so tautly stretched as scarcely to obscure the outlines of the pectoral and intercostal muscles. A light percussion was enough to set these muscles into action like the spread of ripples in a pond. Not only was one aware of the silent nature of the dyspnoea, but on auscultation there was silence or a near approach to it. It was as though the fetch of wind had ceased before it reached the alveoli. On fluoroscopy one saw the small heart within large lung fields, the low disphragm immobile except for slight further flattening when instructed to blow his stomach out, so typical of advanced emphysema. An X-ray film of the chest showed nothing other than emphysema. Here then was a man whose illness began with shortness of breath; who had never been subject to bronchitis or asthma; who had no history of pneumonia; whose days were passed in an outdoor occupation in an exceptionally healthy climate.

This clinical study is based on the observation

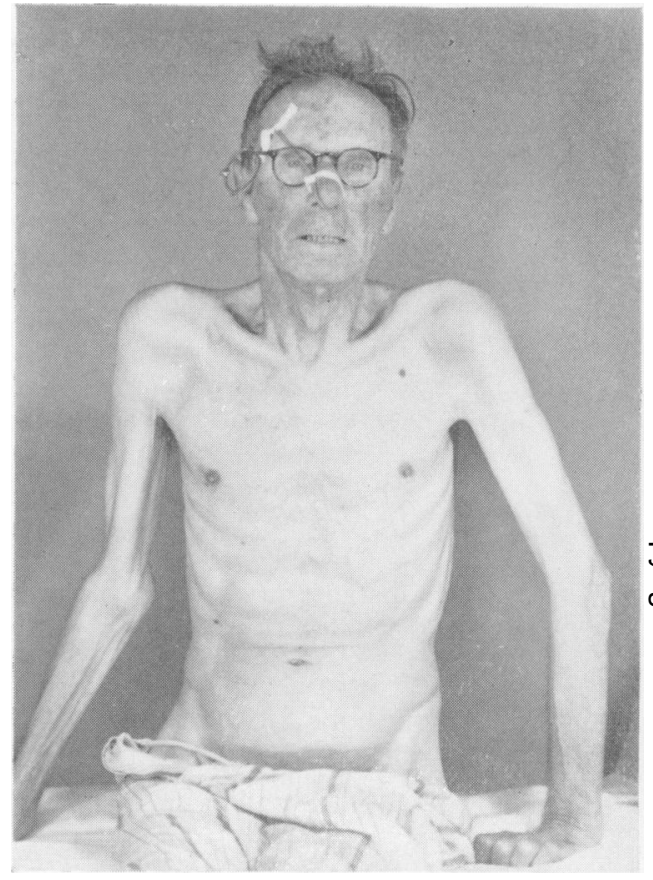

FIg. I.-H.A., aged 63 , has a history of progressive dysnpnoea for twelve years. Note the anxious facies and the tenseness of the accessory muscles of respiration. The limbs and body are wasted to the point of emaciation. He had been confined to bed for many months with the mistaken diagnosis of cardiac failure. Note the intranasal catheter. He had long been addicted to oxygen.

of a great number of people with emphysema, and $\mathscr{N}$ in particular on a close and long-continued study $N^{\circ}$ of 34 patients, all of whom presented with the $\underset{\omega}{N}$ symptom of dyspnoea rather than with asthma and bronchitis.

\section{Sex}

Of these $3+$ patients, 33 were men. It has 0 always been recognized that the disease is more common in men. 


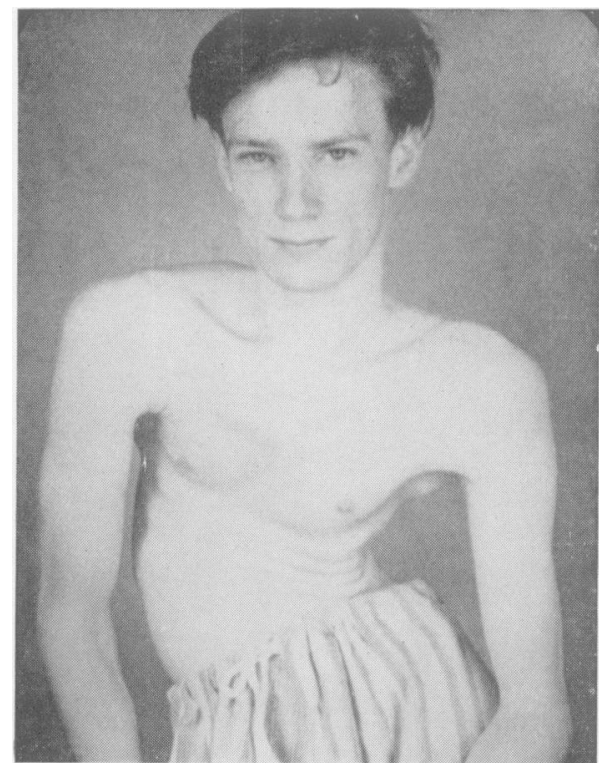

FIG. 2.-This youth suffered from poliomyelitis in childhood. He has gross bilateral bronchiectasis but not emphysema. Despite cough and sputum he is not distressed. Contrast the facies and the accessory respiratory muscles with Fig. I.

\section{Age}

The only woman was first seen at the age of 34 . The average age of all patients when first seen was $5 \mathrm{I}$. The duration of symptoms when first seen was not less than twelve months and up to 12 years. The disease is, therefore, not one of elderly people.

\section{Occupation}

Most of these people had led active, athletic lives and their occupation shed no light on the actiology of the disease. There were four men who had been regular soldiers, two of whom had spent their service lives in the instructional corps. They all had the parade ground posture, which possibly aggravated their difficulty in coping with emphysema.

\section{Infection}

Ten patients gave a history of pneumonia. In five of these the pneumonia occurred when emphysema had already been diagnosed, or long after the dyspnoea had become apparent. (Only one patient related his illness to the pneumonia, but he had been away from work for only two weeks, and an X-ray film of his lungs showed no abnormality after his recovery.

\section{Bronchiectasis}

This was found only once in the series. This man had proven bronchiectasis with postural cough and purulent sputum and clubbed fingers. Nevertheless the whole course of this illness was that of emphysema with recurring spontaneous pneumo-thoraces on either side. Incidentally, this was the only patient with clubbed fingers.

\section{Bronchitis}

This was described in six patients and in only one did it appear that the bronchitis might have been a problem before the advent of dyspnoea.

\section{Wheezing}

Twelve of these patients had a wheeze at some time. It tended to be a late phenomenon long after the patient complained of dyspnoea. Unlike the chronic asthmatic, it was rare to find the chest noisy with rales and rhonci despite the considerable dyspnoea, and often no wheeze was audible, though it might be brought out with exercise.

\section{Dyspnoea}

Though the difficulty in breathing is generally insidious in onset and in its early progress, at times patients will say that they became aware of it comparatively suddenly. In the early stages they may use the terms exhaustion or fatigue rather than shortness of breath, but it is in fact the latter that forces them to slow down or to stop during work. The silent nature of the dyspnoea is evident as the patient moves or undresses and on auscultation the greatly diminished breath sounds are in marked contrast to those heard in compensatory emphysema, in chronic bronchitis, and in asthma. With the relentless progress of the disease, certain characteristics of the dyspnoea may become apparent. It is a distinctive feature of this type of emphysema that the dyspnoea reaches its peak after rising in the morning. Thus R.B., a Union secretary, aged 46 , who sleeps well fully recumbent, describes his shortness of breath as being worse when he gets out of bed in the morning. He gets some relief by standing up and leaning forward, and says that he always eats his breakfast standing up. He improves as the day goes on and is at his best between 10 a.m. and 4 p.m. Cold air upsets him and he is worse after leaving the fireside. This story of the waxing and waning of the dyspnoea is told over and over again. It must be admitted that once a certain stage has been reached, it is rare for the dyspnoea to be arrested or appreciably retarded. Such people may be so distressed that life narrows down to the problem not of food to eat but of air to breathe. In their extremity, patients may sit rigid and immobile 


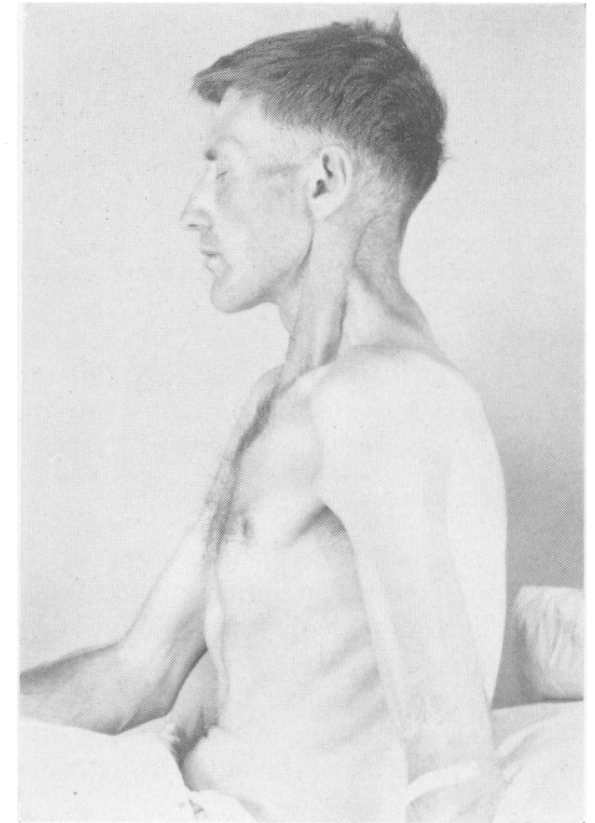

Fia. 3.-W.B., aged +3. He first noticed shortness of breath seven years ago when chopping wood. He had been an athlete and a champion axeman. He had lost four stone in weight in seven years and is totally disabled by dyspnoea. Note that this man has not the conventional barrel chest, and note also the development of the accessory respiratory muscles.

sipping air as though it were hot soup. Generally the descent is gradual but relentless, although it may be interrupted by episodes of more acute dyspnoea. Season and climate, unwonted exertion, or the onset of bronchial spasm may bring about a moderate aggravation. Bronchitis or pneumonia may bring more serious results. 'These patients are prone to episodes of high fever, which come with the suddenness of a malarial attack, often with intense pleuritic pain. A spontaneous pneumothorax may bring about a dramatic change, and so may the increase in tension in a bulla. Cardiac failure, commonly though not necessarily of the right side of the heart, may occur. Finally, there is the imponderable factor of the play of the emotions in the production of dyspnoea in a person already oppressed by an awareness of a bodily function he has always taken for granted and by the effects of a long illness unresponsive to treatment.

\section{Cough}

The mere presence of a cough is not sufficient evidence upon which to base a diagnosis of bronchitis in a patient with emphysema; nor should it

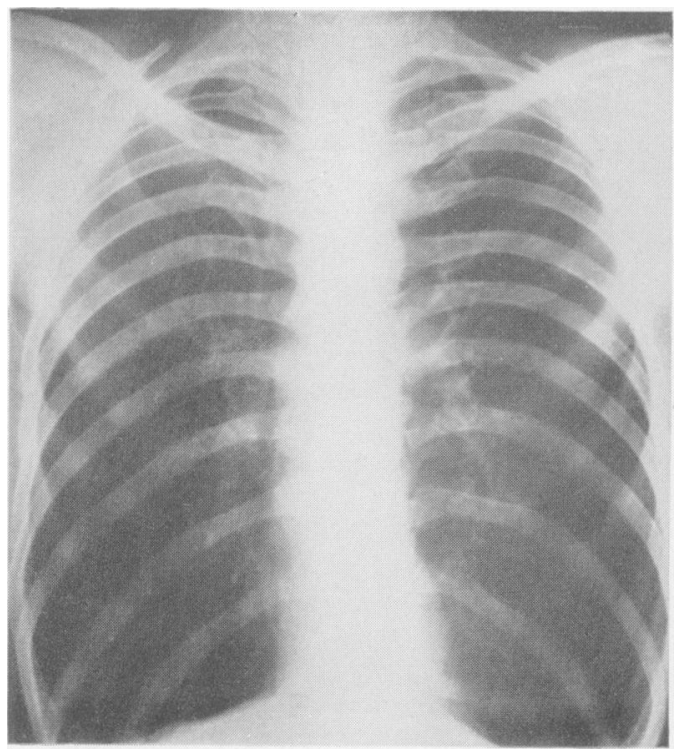

FIG. 4.-X-ray of the chest of patient W.B. (Fig. 3). Note the paucity of the lung markings and extreme narrowness of the heart silhouette.

be assumed that the presence of bronchitis with mucopurulent sputum provides the explanation for emphysema. Insufficient care may be given to the sequence of events. Patients present so often after years of illness with cough and sputum, shortness of breath and a wheeze that the diagnosis of asthma and bronchitis with emphysema is made when the right diagnosis is emphysema followed by bronchitis and bronchospasm.

\section{Loss of Weight}

Nearly all of these patients were of light build but there are few chronic diseases in which loss of weight proceeds so relentlessly over the years. Three patients were seen in whom a provisional diagnosis of carcinoma of the stomach had been made because of anorexia and loss of weight.

\section{Physical Signs}

'The physical signs of emphysema are well known but undue significance has been given to the barrel chest. 'This has not been an obvious characteristic in the patients under discussion.

\section{Radiological Signs}

On fluoroscopic examination it may be found that the diaphragm is virtually immobile, the lung fields are easy to see, and the heart silhouette is small. The pulmonary artery is unusually clearly seen in the left oblique view and often becomes more prominent with the passage of time even in the absence of right heart failure. Cardiac cathe- 


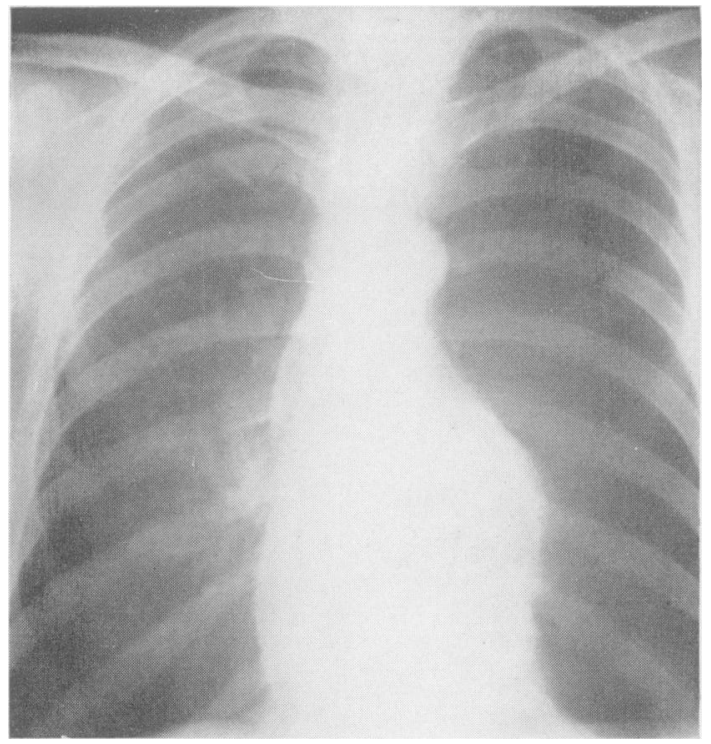

FIG. 5.-A.H., aged 63. He first became aware of serious shortness of breath four years ago. This $\mathrm{X}$-ray at first sight suggests a complete left spontaneous pneumothorax. There is a pneumothorax, but there is also a large tension bulla at the left base (vide Fig. 6).

terization, however, did not show any significant rise in pulmonary artery pressure, yet there is a clarity about the lung fields and a paucity of vascular markings in the periphery that is matched only by pulmonary hypertension.

\section{Complications}

There are two complications which deserve special mention. 'The first is spontaneous pneumothorax. This occurred seven times in 34 patients. 'Two of these patients had recurring pneumothoraces, in one confined to the left lung, in the other affecting both lungs at different times and also associated with mediastinal emphysema. The difficulties in diagnosis can be very great. The presence of a pneumothorax often cannot be diagnosed by physical signs. On percussion there is no demonstrable increase in the resonance already present because of emphysema, and on auscultation the breath sounds are already diminished or absent. The symptoms may be dramatic and the patient appear to be in acute circulatory failure. There is extreme shortness of breath with shallow breathing, pallor changing to a dusky hue, sweating, a rapid weak pulse and a fall in blood pressure. In a very few minutes the patient may be unconscious. Presumably these are the symptoms and signs of anoxia, for recovery is equally dramatic when air is taken off and oxygen given. In less acute forms, the diagnosis is equally

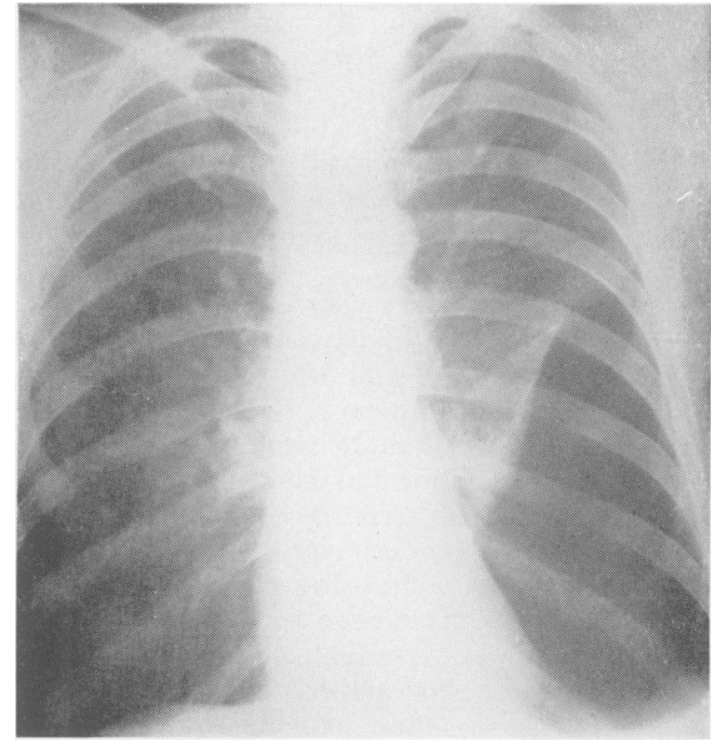

FIG, 6.-A.H., aged 63. The air has now been absorbed from the left pleural cavity. There is re-expansion of the upper lobe. The space in the left lower thorax is a large tension bulla compressing a certain amount of useful lung tissue. There is also bullous emphysema in the right lung.

difficult and in these patients was nearly always made by fluoroscopic examination or by an X-ray film of the chest. An increase of dyspnoea noticed by the patient over one or more days and without an aggravation of bronchitis or a pulmonary infection should call to mind the possibility of a spontaneous pneumothorax.

The second complication, which is equally difficult to diagnose, is due to tension in an emphysematous bulla. The symptoms and signs are commonly those of the less acute forms of spontaneous pneumothorax. The bulla may reach an enormous size and appear to occupy the whole of the hemithorax. It will obscure and compress healthy lung tissue as can readily be demonstrated by the re-inflation that follows thoracotomy and removal of the cyst.

Recognition of these two complications may be vital for the patient's survival and when treated they provide some of the few rewarding experiences in the management of emphysema.

\section{Prognosis}

By coincidence the group of patients upon whom these observations are based include five patients known intimately to the writer for more than 30 years. Two played first-class tennis, one was a rowing blue, and two led the healthy outdoor life of the regular soldier between the two wars. Two of these men have died in great distress from "what 
might he termed pulmonary failure, in their early sixties. Two survive, but in their fifties are in chronic pulmonary failure. The fifth, whose history is known since early childhood, is now aged 55. He had pneumonia two years ago, but no previous history of chest infection. He makes little physical demands on himself and is not often aware of his limitations.

'There have been 1 I deaths and only one of these has been clearly due to cardiac failure. Most of these patients have died comparatively suddenly and one at least from an unsuspected pneumothorax. One patient quietly expired with breathing so shallow that he appeared merely to sip air. Two patients died with a terminal bronchopneumonia. Two patients have been seen with episodes of right heart failure, one being the only woman in the series. Both have been redeemed from their failure rather more easily than is the case with systemic hypertension and left heart failure.

'Though one sees these patients over many years and the prospect is for years of life, the disease is a distressing one. Indeed if we recognize malignant hypertension, we should recognize that there is a malignant form of emphysema.

\section{Treatment}

I know of no form of treatment mentioned in the literature that has not been tried for these patients. These include breathing exercises, the relief of infection, the control of bronchial spasm, the use of oxygen by mask, catheter and tent, the empirical use of cortisone, pneumoperitoneum, abdominal binders and psychotherapy. Some of these may be palliative; none has had any appreciable effect on the progress of the disease.

On one occasion, when it seemed justifiable to try any method that might give the patient a rest from his misery, controlled respiration was used after anaesthesia with pentothal, preceded by omnopon and scopolamine and with the addition of flaxedil. 'This was the most distressing case in the writer's experience, and at least it was shown that the anaesthesia did not endanger the patient's life.

Every patient with emphysema should be taught breathing exercises. It is uncommon for these to bring about much obvious improvement, but on rare occasions they do so and it is not easy to predict those who will have nothing to gain from them. Emphysematous patients readily become addicted to oxygen and its use is not without danger. It should be withheld as long as possible.

The surgical treatment of emphysema is of limited value but there are special indications. These are, firstly, the relief of tension in emphysematous bullae, more particularly when it is probable that useful lung tissue is being compressed. 'The second indication is in the treatment

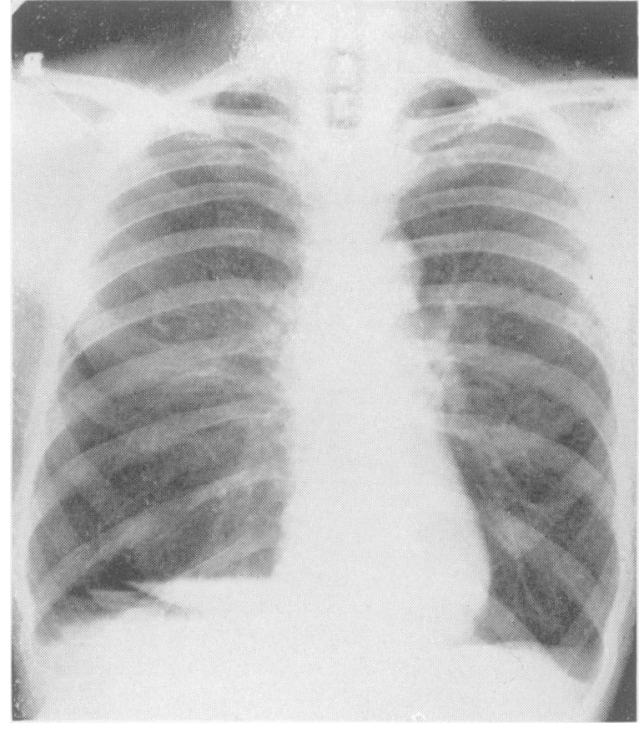

Fig. 7.- Recurrent spontaneous pneumothorax. Note the partial collapse of the right lung and fluid levels in several emphysematous bullae at the right base.

of recurring pneumothorax, and particularly when the collapsed lung fails to re-expand. Thoracog of tomy, removal of the walls of bullae, and the re expansion of the remaining lung tissue wite obliteration of the pleural space can be a most satisfying operation. The third indication which has been followed has been thoracotomy and removal of bullae for the reason that they are dead $\AA$ spaces and a hindrance to satisfactory respiration. This has been the least successful operation.

\section{Discussion}

'The 34 patients upon whose records this paper is based all suffered from chronic pulmonary 3 failure. This term embraces the two functions of ventilation and respiration. Ventilation is a mechanical process concerned with the movement of of air between the atmosphere and the alveolo- 3 capillary membrane. Failure of function is responsible for dyspnoea.

Respiration is a physico-chemical process concerned with the diffusion of oxygen from alveolar $N$ spaces into the blood and the diffusion of carbon dioxide from blood to alveolar air. Failure of $\tilde{O}$ function is responsible for anoxia and cyanosis. స్ట These two divisions of function are not clear-cut because ventilatory insufficiency, if severe enough, will necessarily induce respiratory insufficiency, and on the other hand, respiratory insufficiency will stimulate the respiratory centre and lead to increased ventilation.

Sir James Kingston Fowler (1898) wrote: 'All 


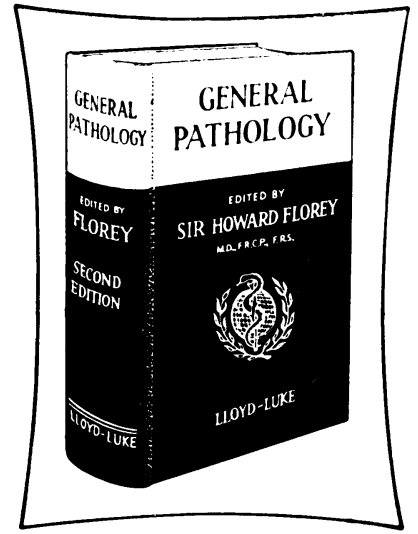

\section{Books that enshrine profound thought GENERAL PATHOLOGY \\ (2nd edition) edited by SIR HOWARD FLOREY, M.D., F.R.C.P., F.R.S. Professor of Pathology, University of Oxford}

The call for a second edition of this book, which appeared first under the title Lectures on General Pathology, has enabled the authors to revise its contents and add new chapters on thrombosis, metabolic changes following injury, atherosclerosis and tumours, thus enhancing its value by covering a wider field.

xvi $932 \mathrm{pp} . \quad 410$ illustrations 3 colour plates (2nd edition 1958) Just published

84s. net

\section{RECENT TRENDS IN CHRONIC BRONCHITIS}

edited by NEVILLE C. OSWALD, M.D.(Cantab.), F.R.C.P.(Lond.)

Physician, St. Bartholomew's and Brompton Hospitals, London; Honorary Physician to H.M. The Queen

The main purpose of this book is to bring together under one cover for the first time recent views upon the various facets of chronic bronchitis. Much of the text consists of the original work of the several contributors. Culled from their experiences with chronic bronchitis at the Brompton Hospital since 1950, the authors present their views on the diagnosis, prevention and treatment of this distressing and often killing disease.
viii if 200 pp.
76 illustrations, 2 colour plates
(1958) 30s. net
Just published

\section{LLOYD-LUKE (Medical Books) LTD., 49 Newman Street, W.I}

who have studied the subject of emphysema from a clinical standpoint must have met with cases in which the ordinary exciting causes of the disease have apparently been absent.' Kountz and Alexander (1934) and Christie (1944) have made the same comment. It appears to the writer that the clinical association of chronic bronchitis with emphysema has brought little but confusion to the study and understanding of emphysema. It is not what happens in the bronchial tubes that is important, and neither bronchitis nor bronchiectasis will lead to emphysema unless there is bronchiolitis as well. Bronchitis and bronchiectasis are both associated with a cough, but the cough itself will not lead to emphysema unless there is bronchiolitis.

This group of 34 patients developed emphysema without bronchitis. There can be no doubt that the seat of their disease was in the bronchioles and alveoli. In this region the cough reflex is virtually non-existent so that the single presenting symptom was dyspnoea. It seems logical to infer that the one essential feature of emphysema is bronchiolitis, and there is much to support this in the excellent studies of McI,ean (1956). The predominance in males is unexplained, but the same predominance exists in spontaneous pneumothorax.

\section{Summary}

Observations are made on the clinical study of 34 patients who presented with the complaint of shortness of breath without preceding bronchitis or asthma.

Thirty-three of these patients were males.

This form of emphysema begins commonly in the fourth and fifth decades and proceeds relentlessly to chronic pulmonary failure rather than to cardiac failure.

The features of the dyspnoea are described as well as the constitutional disturbance.

The relationship of emphysema to bronchitis is discussed.

\section{BIBLIOGRAPHY}

(IIRISIIIE, R. V. (194t), Brit. med. Y., i, I +3

FOWLER, J. K., and GODLEE, R. J. (1898), 'The Diseases of the l.ungs,' Longmans, Green \& Co., London.

KOLNTZ, W. B., and ALEXANDER, H. L. (1934), Emphysema Medicine (Baltimore), $13,25 \mathrm{I}$

MclEAN, K. H. (1956), 'The Pathogenesis of Pulmonary Emphysema.'

'Thesis for Doctorate of Philosophy,' University of Melbourne. 